\title{
La tríada cultural-contextual: Una oportunidad para asegurar la pertinencia cultural en la implementación de la educación intercultural ${ }^{*}$
}

\author{
Cultural-contextual triad: An opportunity to ensure cultural relevance in the \\ implementation of intercultural education
}

\author{
Tríade cultural-contextual: uma oportunidade para garantir a pertinência cultural na \\ implementação da educação intercultural
}

\author{
Nolfa Ibáñez Salgado. ${ }^{a}$ \\ a Universidad Metropolitana de Ciencias de la Educación, Chile. Fono: 56-222412641. \\ Correo electrónico: nolfa.ibanez@umce.cl
}

\begin{abstract}
RESUMEN
Con base en resultados de investigación, se pretende contribuir a mejorar la implementación de la Educación Intercultural en Chile en lo relativo a su pertinencia cultural, cuestión que ha sido criticada como insuficiente por sus beneficiarios, especialmente por el pueblo Mapuche, así como por informes nacionales e internacionales y otros resultados de investigación. En el nuevo escenario que se configura en las escuelas rurales del sur de Chile con la incorporación al currículo del Sector de Aprendizaje de Lengua Indígena, obligatorio para las escuelas con alta matrícula indígena, el artículo releva el potencial rol de quienes conforman lo que llamamos tríada culturalcontextual -profesores, educadores tradicionales y apoderados mapuche- que podría convertirse en un eje principal para generar cambios que permitan disminuir las brechas de implementación, asegurando la participación efectiva de quienes son, al mismo tiempo, destinatarios de la política pública de educación intercultural y encargados de llevarla a la práctica.
\end{abstract}

Palabras clave: educación intercultural, participación de los actores, pertinencia cultural.

\begin{abstract}
Based on research results, our goal is to make a contribution to the enhancement of the implementation of intercultural education in Chile. Particularly regarding to its cultural pertinence, an issue that has been repeatedly doomed insufficient by national and international reports, the available research, and, especially, by the Mapuche people. The incorporation of indigenous languages as a curricular requirement for those schools with a high quantity of indigenous students has made up a new scenario, incorporating new actors and new (expected) classroom dynamics. In this context, this paper explores the potentialities contained in the roles of those who make up what we call cultural-contextual triad -teacher, cultural educator, and Mapuche parents-, which we believe could become a nodal point for generating the changes needed in order to reduce implementation gaps, and ensuring effective participation of those who are at the same time beneficiaries and responsible for executing intercultural policy within our country.
\end{abstract}

Key words: intercultural education, participation of the actors, cultural pertinence.

\section{RESUMO}

Com base nos resultados de pesquisa, pretende-se contribuir na melhora da implementação da Educação Intercultural no Chile, no que diz respeito a sua pertinência cultural, questão que tem sido apontada como

El artículo forma parte del Proyecto Fondecyt N¹111030/2011-2014. 
insuficiente por parte de seus beneficiários, especialmente pelo povo Mapuche, assim como pelos relatórios nacionais e internacionais e resultados de pesquisa. No novo cenário configurado em escolas rurais no sul do Chile, com a incorporação obrigatória do Setor da Aprendizagem da Língua Indígena ao currículo, para as escolas com alta matrícula indígena, o artigo destaca o papel potencial das pessoas que compõem o que chamamos tríade cultural-contextual -professores, educadores tradicionais e representantes Mapuche- o que poderia tornarse o eixo principal para gerar mudanças que reduzam lacunas de implementação, assegurando a participação efetiva daqueles que são os destinatários da política pública da Educação Intercultural e, ao mesmo tempo, os responsáveis por sua execução prática.

Palavras chave: educação intercultural, participação dos atores, pertinência cultural.

\section{INTRODUCCIÓN}

El presente artículo surge del análisis y la reflexión sobre lo que hemos aprendido y comprendido en tres años de investigación, durante los cuales hemos indagado sobre las concepciones que familias mapuche de las Regiones de La Araucanía y de Los Ríos y familias aymara de la Región de Arica y Parinacota tienen del aprendizaje, la educación y la escuela. En el desarrollo de este estudio hemos trabajado, en conjunto y sistemáticamente, con los integrantes de 14 familias extendidas, la mayoría compuesta por tres generaciones, con el propósito de construir en conjunto las bases de una dimensión intercultural para el currículo oficial de educación parvularia y primer ciclo de enseñanza básica. Entre los integrantes adultos de las familias mapuche hay pequeños agricultores, profesores y educadores tradicionales de comunidades rurales que, en su mayoría, son también apoderados o apoderadas en escuelas de sus respectivos sectores.

Este artículo se circunscribe a la implementación de la Educación Intercultural Bilingüe (EIB) dirigida al pueblo mapuche del sur del país, considerando aspectos que han emergido como relevantes del análisis de los datos recogidos hasta ahora en nuestra investigación. Si bien la implementación de la EIB no es el foco del estudio, los resultados preliminares en torno a este ámbito y que consideran las opiniones y propuestas de nuestros colaboradores mapuche, podrían orientar modificaciones relativas a su pertinencia cultural desde la perspectiva de quienes son sus destinatarios, en un momento en el cual se han establecido nuevas acciones para mejorar dicha implementación, específicamente la instauración de las duplas pedagógicas, lo que configura un nuevo escenario que constituye una oportunidad para identificar, definir y priorizar aspectos principales de pertinencia cultural que sean percibidos como tales por quienes pertenecen al pueblo mapuche.

En efecto, este nuevo escenario permite visualizar al grupo de actores que conforman lo que hemos llamado 'tríada cultural-contextual' -profesores, educadores tradicionales y apoderados mapuche-; una tríada inédita constituida por personas que son potenciales agentes de cambios profundos, ya que su actuación en lo educacional abarca, simultáneamente, dos dimensiones de experiencia de vida en las cuales son protagonistas: destinatarios de la política pública de EIB y actores encargados de llevarla a cabo. El artículo pretende relevar esta cuestión para contribuir, por un lado, al aseguramiento de una adecuada pertinencia de los programas de educación intercultural impulsados por la política pública chilena y, por otro lado, a evidenciar aspectos que parecen no haber sido suficientemente considerados en ella, los que surgen reiteradamente como necesidades sentidas en los discursos y propuestas de cambio de las personas mapuche. 


\section{CONTEXTUALIZACIÓN}

Desde el punto de vista conceptual, la Educación Intercultural Bilingüe es concebida por la política pública chilena como "una práctica educativa ligada a la pertinencia de los aprendizajes, a la contextualización de los contenidos didácticos, a la centralidad del niño como eje que ha de orientar la práctica pedagógica con la participación de la familia y de las comunidades" (MINEDUC, 2000: 1). El Programa de Educación Intercultural Bilingüe (PEIB) se instala como política pública dependiente del Ministerio de Educación a partir de 1996, con base en la Ley №1 9253 de 1993, a partir de la cual se crea la Corporación Nacional de Desarrollo Indígena, CONADI, cuyos objetivos son la promoción, la coordinación y la ejecución de los planes de desarrollo que están dirigidos a las personas pertenecientes a los pueblos originarios.

En 2001 se establece el convenio con el Banco Interamericano de Desarrollo para fomentar el desarrollo de las comunidades indígenas en Chile, y el programa OrígenesBID-CONADI se incorpora al PEIB con la Educación Intercultural Bilingüe como parte de uno de sus componentes. Este programa se desarrolla en dos fases, la segunda termina en 2011 y la evaluación de medio término, realizada en 2009-2010, señala retrasos en su implementación, pero constata la incorporación al PEIB de 196 escuelas en el período, de las cuales el 51\% son de la Región de La Araucanía, la mayoría rurales (Sur Profesionales Consultores, 2010).

El informe final de la evaluación de esta segunda fase señala que, en general, se consideran pertinentes las acciones desplegadas en este componente, y que se supera la meta de escuelas con PEIB y profesores capacitados, pero también indica que las horas destinadas a esas capacitaciones son variables, que no hubo un sistema para recoger el grado de satisfacción de los usuarios, y que "sólo se cuenta con antecedentes sobre actividades y sus beneficiarios -docentes, alumnos, [...]-, sin precisar si tienen relación con la población objetivo definida para el programa, o sea, no se puede determinar si los profesores capacitados realizan su actividad docente en escuelas pertenecientes a las comunidades atendidas" (Ministerio de Planificación/Corporación Nacional de Desarrollo Indígena, 2010: 166).

En el nuevo contexto para la EIB que configura el Decreto 280 del MINEDUC (2009), al incorporarse al currículo el Sector de Aprendizaje de Lengua Indígena (SLI), los educadores tradicionales, continuadores o herederos de la figura del asesor cultural pasan a conformar un nuevo sistema de trabajo con el profesor o profesora, denominado 'dupla pedagógica', constituida por el docente a cargo del curso, que es el profesor mentor, y el educador tradicional, que es miembro de la comunidad a la que pertenece la escuela. De acuerdo a este Decreto, a partir de 2010 se incorporan al currículo nacional los Objetivos Fundamentales y Contenidos Mínimos Obligatorios del SLI para los niveles de $1^{\circ}$ a $8^{\circ}$ año básico, cuya implementación debe considerar progresivamente un nivel educacional más por año, esto es, se debería completar hasta $8^{\circ}$ básico en 2017.

El SLI tiene carácter obligatorio para las escuelas que poseen una matrícula indígena superior al 50\%, y un carácter progresivo al $20 \%$ para el año 2014, pero es optativo para las familias, quienes deben firmar un documento en el cual expresan su deseo de que su hijo o hija tenga como parte de su currículo el nuevo sector. En Chile, el 70\% de los establecimientos educacionales posee matrícula indígena (Gobierno de Chile, 2011), pero el $79 \%$ no alcanza el porcentaje requerido de matrícula de estudiantes indígenas para hacer 
Estudios Pedagógicos XLI, N 1: 323-335, 2015

LA TRÍADA CULTURAL-CONTEXTUAL: UNA OPORTUNIDAD PARA ASEGURAR LA PERTINENCIA CULTURAL EN LA IMPLEMENTACIÓN DE LA EDUCACIÓN INTERCULTURAL

obligatoria la implementación del SLI, por lo que la mayoría de los estudiantes indígenas en Chile no tendría la oportunidad de asistir a cursos en los que se implemente este sector de aprendizaje (Carvajal y Dresdner, 2012).

En nuestro país, más del $11 \%$ de la población, un millón ochocientos cuarenta mil personas, pertenece a algún pueblo originario. La mayor población indígena corresponde al pueblo mapuche, con un 84,11\%. En las Regiones de La Araucanía y de Los Ríos reside el 53,54\% de la población mapuche. La Región de La Araucanía tiene los mayores índices de pobreza y extrema pobreza del país, y está entre los más bajos resultados en las mediciones educacionales. En esta región vive el 31,26\% de la población mapuche, la mayoría en la ruralidad (Ministerio de Desarrollo Social, 2013, 2012; MINEDUC, 2012, 2010). Esta región tiene el mayor número de escuelas que han sido focalizadas por el PEIB, o que han establecido programas propios de EIB y que, a partir de 2010, han debido incorporar al currículo el nuevo Sector de Aprendizaje de Lengua Indígena.

Los pueblos originarios, en especial el pueblo mapuche, han manifestado reiteradamente su disconformidad tanto con aspectos de la implementación de las políticas públicas de educación y desarrollo que consideran poco pertinentes, como por diversos aspectos que estas políticas dejan de abordar: "se pueden observar posturas críticas y discusiones sobre las políticas de desarrollo [incluida educación] que se han venido implementando en el país en las últimas décadas; se escucha desde el mundo indígena que ellas no serían compatibles con sus tradiciones, costumbres y expectativas" (Programa de las Naciones Unidas para el Desarrollo-Gobierno de Chile, 2008: 8). En el mismo sentido, en el diagnóstico sobre la situación de los pueblos originarios realizado en 2008 por el Gobierno de Chile, se explicita que "la institucionalidad pública creada en 1993 ha entrado en crisis. Los indígenas sostienen que su problemática no ha sido asumida en forma integral (...) finalmente, la sociedad en su conjunto no acepta la multiculturalidad ni vela por la inclusión e integración plena de los pueblos indígenas" (2008: 2). En el año 2006, diversas agrupaciones mapuche elaboraron un documento titulado "Propuestas de Organizaciones Territoriales Mapuche al estado de Chile", el cual, en relación a la educación intercultural, señala:

la implementación del PEIB, depende a veces de la buena voluntad de los gobiernos locales o regionales, a lo que se sumaría resistencia e ignorancia de los cuerpos docentes locales y la visión racista de la sociedad chilena. Estas limitaciones hacen inaplicable en la práctica las políticas de educación intercultural, que tampoco consideran la participación directa y deliberativa de las comunidades Mapuche. Sólo se profundiza la folcklorización de nuestra cultura y conocimientos (Organizaciones Territoriales Mapuche, 2006: 40).

Lo anterior es en parte ratificado por el estudio de la Comisión Económica para América Latina y el Caribe (CEPAL) sobre la exclusión social del pueblo mapuche, que destaca el hecho de que las personas mapuche sienten que sus saberes sobre el mundo y la naturaleza, los que se transfieren tanto oral como vivencialmente de generación en generación, "no están considerados en los modelos de enseñanza-aprendizaje oficiales" (2012: 96). En la misma dirección, el informe del Relator Especial de Naciones Unidas (2009) sobre derechos de los pueblos indígenas señala que ha constatado en Chile "la

Los resultados del Censo 2012 fueron publicados por el Ministerio de Desarrollo Social y luego retirados. Actualmente se encuentran en revisión. 
existencia de un nivel significativo de desconfianza, descontento y hasta rechazo de los planes, programas y políticas del Gobierno por parte de los pueblos indígenas" (Anaya, 2009: 6), y que la política de educación intercultural bilingüe se mantiene restringida a pocas escuelas, sin recursos económicos, ni personal técnico capacitado que den seguimiento a su implementación. Esto último es advertido también en el reciente Examen sobre el Informe presentado por Chile ante el Comité de la Convención Internacional sobre la Eliminación de todas las Formas de Discriminación Racial, donde se lamenta el hecho de que sólo se consideren los niveles básicos para la EIB, y que el número de estudiantes indígenas que pueden acceder a estudiar su lengua originaria tras la inclusión del SLI sea tan restringido (Naciones Unidas, 2013).

En relación al PEIB y su implementación, la investigación disponible, incluyendo nuestros estudios previos, muestra que, en general, existe una escasa apropiación y valoración de este programa por parte de los distintos actores. Al mismo tiempo, se constata que las prácticas en aulas con mayoría de estudiantado indígena no parecen incluir contenidos o aspectos interculturales contextualizados en el mundo cotidiano de los alumnos, de acuerdo a lo explicitado en las orientaciones de ese programa.

La Educación Intercultural Bilingüe parece ser percibida como una educación que sólo interesa y atañe a las personas indígenas, "desconociéndose su valor universal y su incidencia en la educación general" (Carihuentro, 2007: 117), y constituyendo sólo "un suplemento al programa general de enseñanza o una especie de 'concesión' a los mapuche" (Rother, 2005: 80). La EIB se visualiza también como una simple traducción al idioma indígena que no aportaría a un mayor y mejor conocimiento de la propia cultura, ni a su valoración, ni "a la construcción de nuevos aprendizajes a partir de lo conocido, cercano y significativo" (Hevia, 2005: 102). Hevia también señala que la contextualización del currículo a los estudiantes de los pueblos originarios sería una estrategia para revertir sus bajos resultados en las pruebas SIMCE, "de modo que el aprendizaje fundamental se convierte en el dominio de los códigos de la cultura dominante para su inserción en la sociedad globalizada" (2005: 101-102), en circunstancias que la interculturalidad es mucho más que el bilingüismo en amplitud y complejidad. Ésta trasciende la sola cuestión del idioma por cuanto hace referencia al proceso dialogante entre tradiciones culturales distintas, imbricando sus diversos aspectos, donde la lengua es sólo uno de éstos, y entre los cuales tienen particular relevancia los aspectos intangibles y simbólicos propios de cada cultura (Serrano y Rojas, 2003; Zúñiga y Ansión, 1997).

Por otra parte, diversos estudios constatan la falta de correspondencia entre el discurso de la EIB que profesoras y profesores declaran aceptar y lo observado en la práctica pedagógica (Ibáñez, 2010a; Ibáñez, Druker y Rodríguez, 2009; Leyton, Mancilla, Navarrete y Painean, 2005; Lobos y Águila, 2004). Así también se verifica la falta de información que éstos/as tienen acerca de lo que están realizando otros subsectores del programa, lo que redundaría en el poco compromiso de las personas en general con la EIB (Riedemann, 2008; Montecinos, 2007; Fernández, 2003). La mayoría de los trabajos citados coincide en señalar que la falta de participación de los propios estudiantes, de sus familias y de las comunidades en los proyectos de EIB de las escuelas constituye uno de los principales problemas. En un sentido similar, un reciente estudio realizado en una escuela rural multigrado de La Araucanía, y cuyo objetivo fue conocer el efecto del PEIB en la identidad mapuche, concluye que este programa no propicia el diálogo entre culturas porque se limita sólo a algunos indígenas, y no mantiene una identidad étnica, "solamente 
da una apariencia respecto a que se están realizando cambios, pero la verdad es que el PEIB solamente refuerza la hegemonía de la dominancia eurocéntrica en la sociedad chilena" (Miller, 2012).

Específicamente en relación a la dupla pedagógica, los primeros estudios de los cuales disponemos en el marco de la incorporación del SLI ya identifican problemas similares a los señalados. Acuña advierte sobre la debilidad de los procesos de supervisión y acompañamiento de los educadores tradicionales por parte de los profesores mentores, unido al hecho de que "un alto porcentaje de las clases se realiza en el aula y que existen pocas instancias de integración con la comunidad, así como de contenidos exteriores a la escuela" (2012: 24). Esta distancia entre la escuela y la comunidad local también es destacada por el estudio sobre la implementación del SLI encargado por MINEDUC y UNICEF (2012), que consigna este aspecto como uno de sus hallazgos. Otro estudio encargado por MINEDUC en 2011 sobre la implementación de la EIB también muestra resultados equivalentes: "PEIB-Orígenes no se asemeja a las propuestas conceptuales que se encuentran en la literatura. Parece más un programa para la educación focalizada de niños indígenas, que un programa intercultural propiamente tal, ya que no considera elementos fundamentales como la promoción de las culturas originarias en la gran sociedad" (2011: 101). Esto también es ratificado por la investigación sobre el currículo del SLI realizada por Quintrileo, Yáñez y Valenzuela, la que señala: “en la propuesta del PEIB se evidencia un tipo de interculturalidad funcional, en la medida en que se promueve una identidad indígena estática y estereotipada, que ignora el dinamismo de las identidades sociales, culturales y étnicas" (2013: 59).

Todo lo anterior indica la urgencia de establecer modificaciones a la implementación de la EIB, que puedan corregir a tiempo las debilidades que ya se detectan en la implementación del nuevo Sector de Aprendizaje de Lengua Indígena, para que no se desdibuje la oportunidad que significa su inclusión en el currículo. Ésta, más allá de otorgar la posibilidad de aprender su lengua al estudiantado mapuche, puede marcar el inicio de la construcción de una educación realmente intercultural, que considere como eje principal la perspectiva de los actores, sus modos propios de concebir el mundo y la relación con los otros.

\section{UN CAMINO POSIBLE}

Comprendemos la educación intercultural como un modo de avanzar hacia una propuesta educativa que brinde el espacio para la construcción democrática de identidades nacionales inclusivas, y de sociedades donde la interculturalidad de hecho se transforme también en interculturalidad de derecho. En este marco, el cambio de mirada considera el desplazamiento desde el enfoque de la interculturalidad como innovación curricular dirigida a las poblaciones indígenas, hacia el posicionamiento de un enfoque intercultural como eje estructurador del currículo nacional, sustentado en un diálogo interepistemológico de saberes (Ibáñez, Díaz, Druker y Rodríguez, 2012; Ibáñez, 2010b; García, 2008; Ansión, 2007; Schmelkes, 2006; Prada, 2003; Zúñiga y Ansión, 1997).

Pese a que más de la mitad de los y las estudiantes indígenas son minoría dentro de sus establecimientos educacionales y en sus aulas, la incorporación del SLI ha significado una mayor participación de educadores tradicionales, participación que irá en aumento año a año, 
especialmente en las regiones con mayor población mapuche. Como se señaló antes, las escuelas que alcanzan el porcentaje de estudiantado indígena requerido para la implementación curricular de este nuevo sector de aprendizaje se concentran principalmente en las regiones del sur del país y, dentro de éstas, en La Araucanía, siendo en su mayoría escuelas rurales.

Consecuentemente, en esa región se ha instalado el mayor número de duplas pedagógicas (Acuña, 2012). Si la participación de educadores tradicionales se concreta en 2014 para todas las escuelas del sur del país que tengan más del 20\% de estudiantes mapuche, y se cumple la contratación paulatina de profesores mapuche de Educación Básica para impartir docencia en el SLI, estarían dadas las condiciones para generar nuevos espacios educativos realmente interculturales, al menos en lo concerniente a las comunidades escolares de esos establecimientos, principalmente por tres razones:

- Doble validación de los educadores tradicionales. Los educadores y educadoras tradicionales poseen una doble validación: la primera corresponde a la de sus propias comunidades, ya que para ejercer como tales deben ser validados por sus comunidades de referencia como poseedores de los valores y conocimientos ancestrales de su pueblo, así como de las habilidades necesarias para transmitirlos en la escuela, además de existir un reconocimiento a sus capacidades de liderazgo. La segunda corresponde a una mayor validación de estas personas mapuche en la cultura escolar, precisamente por el hecho de haber sido seleccionados/as por sus comunidades, ya que esto implicaría también que tienen estudios en el sistema educacional y que han participado en capacitaciones, es decir, que poseen conocimientos formales que son valorados por la cultura dominante.

- Configuración de un espacio inédito de convivencia intercultural. Educadores tradicionales y profesores mentores establecerían un sistema de trabajo conjunto que, con independencia de su mayor o menor efectividad en cuanto a resultados de aprendizaje de contenidos de sus estudiantes, implica necesariamente una convivencia prolongada de dos personas que, según las cifras disponibles (Acuña, 2012), hoy pertenecen mayoritariamente a culturas distintas. Esto genera un nuevo espacio de trabajo conjunto intercultural, en el cual dos personas que provienen de distintas tradiciones culturales, con una experiencia de vida cotidiana guiada por las lógicas de convivencia propias de sus culturas, se encuentran en la escuela en función del cumplimiento de un objetivo común; cuestión que abriría mayores y mejores posibilidades para que estas personas conozcan, comprendan y puedan articular sus respectivas concepciones sobre interculturalidad y educación.

- Posible nuevo escenario para la participación de la familia y la comunidad mapuche en la escuela. Por el promedio de edad de las y los educadores tradicionales, levemente superior a los 40 años y con una mayoría alrededor de los 30 (Acuña, 2012), es posible suponer que, muy probablemente, ellos/as son también apoderados/as de sus hijos e hijas en las mismas escuelas en las cuales se desempeñan, o en escuelas cercanas o de la misma región, lo que sería similar en el caso de los profesores mentores que pertenezcan al pueblo mapuche y que irán siendo contratados paulatinamente por el PEIB para hacerse cargo del SLI. Este nuevo escenario donde los/as apoderados/as que son al mismo tiempo docentes o educadores tradicionales podría modificar la situación de poca participación que tiene la familia y la comunidad mapuche en la escuela, y que ha sido reportada por la investigación.

Los/as apoderados/as de escuelas con programas de EIB, las profesoras y profesores mentores, mapuche y no mapuche, y las educadoras y educadores tradicionales validados por sus comunidades para conformar la dupla pedagógica en la implementación del SLI, constituyen una triada cultural-contextual que, al mismo tiempo que es destinataria de 
una política pública específica, tiene entre sus integrantes a quienes son los encargados y encargadas de llevarla a la práctica. Al ser la falta de una adecuada pertinencia cultural la mayor crítica al PEIB desde el pueblo mapuche, esta tríada cultural-contextual puede ser una de las bases fundamentales para iniciar cambios en los modos en los cuales se ha diseñado hasta ahora la implementación del PEIB, respecto a asegurar la pertinencia cultural de las acciones a seguir para cumplir los objetivos de dicho programa, de modo que dicha pertinencia sea reconocida como tal por sus beneficiarios.

Entendemos también que existen múltiples aspectos en relación con las tres razones esgrimidas que pueden hacer fracasar lo que ahora vemos como una gran oportunidad, especialmente en lo relativo al rol que adoptan educador tradicional y profesor mentor en el quehacer de la sala de clases. Si la dupla pedagógica se convierte en el reflejo de la cultura dominante-cultura subordinada, esta convivencia entre profesional y educador tradicional sólo serviría para seguir reproduciendo las condiciones de inequidad educativa en las que se desenvuelven los pueblos originarios. Dicho de otro modo, si la incorporación del educador tradicional y del profesor mapuche a los programas de EIB es tratada sólo como una acción afirmativa más hacia los pueblos originarios, y no como un cambio estructural en los modos de relación al interior del aula, no existirá el espacio inédito de convivencia intercultural que tiene hoy la posibilidad de ser generado, ni tampoco un nuevo escenario que propicie una mayor participación de la familia en la escuela.

Los datos de los que disponemos en la actualidad sobre la percepción de educadores tradicionales integrantes de la dupla pedagógica permiten visualizar algunos de los principales problemas que deberían corregirse con celeridad por parte del PEIB. Uno de éstos refiere a los aspectos que estarían a cargo de uno y otro integrante de la dupla: la mantención de la disciplina en la sala de clases estaría hoy mayoritariamente a cargo del profesor mentor, no se permitirían desplazamientos por la sala ni conversaciones entre estudiantes, suponemos que con el propósito de que el educador tradicional pueda tener mejores condiciones para ejercer su labor. Esto, a nuestro juicio, pone un marco lógico de control propio de la cultura dominante, que desdibuja el rol del educador tradicional en el aula como ejecutor de modos de hacer propios de su cultura, lo que "podría resultar contradictorio con la noción de lógicas de enseñanza aprendizaje novedosas y variadas" (Acuña, 2012: 22) y, especialmente, podría limitar o impedir que la convivencia en el aula también ocurra bajo las lógicas que guían la convivencia en la cultura distinta a la dominante. Dicho en otras palabras, podría limitar o impedir la generación de un espacio relacional realmente intercultural en la escuela.

También se visualiza la falta de una adecuada pertinencia cultural en los materiales que se entregan por parte del PEIB a quienes conforman esta dupla. Los educadores tradicionales a quienes hemos entrevistado consideran como una dificultad el uso de este material, porque muchas veces su contenido no corresponde al contexto, lo que es ratificado en las respuestas a la consulta efectuada por el estudio del MINEDUC a los educadores tradicionales respecto de la guía pedagógica que deben utilizar:

- Carece de indicaciones sobre cómo adecuar los contenidos al contexto cultural y lingüístico local.

- Presenta contenidos culturales sin contexto: no especifica dónde fueron recogidos u observados los relatos o prácticas culturales recopiladas.

- Impone una cultura escrita a realidades donde predomina la transmisión oral (Acuña, 2012: 26). 
Otro de los problemas detectados por los estudios citados es la falta de contacto y articulación de los programas escolares de EIB con la comunidad local. En este caso se hace referencia mayoritariamente al lugar en donde viven los estudiantes y los educadores tradicionales.

Los problemas mencionados podrían superarse si la política pública ideara tempranamente estrategias periódicas y sistemáticas para escuchar las voces de la tríada cultural-contextual, pero bajo un sistema que no siguiera las lógicas de la cultura dominante de las que surge la oferta educativa que el Estado chileno hace en general, sino siguiendo las lógicas del pueblo originario del cual se trate, en este caso, el pueblo mapuche.

Los resultados preliminares de nuestra investigación en relación con las prioridades y las valoraciones sobre los modos de enseñar y aprender desde la perspectiva de las numerosas personas mapuche que nos colaboran ${ }^{2}$, permiten establecer orientaciones en torno a las formas de implementación del currículo que, más allá de contenidos programáticos, consideran las lógicas propias de la convivencia de las personas mapuche en sus familias y sus comunidades. Entre otros aspectos, las personas mapuche con quienes hemos trabajado valoran la enseñanza y el aprendizaje del respeto al otro, el respeto a la opinión de las personas mayores, a la naturaleza y a las cosas sagradas propias de su cultura que constituyen una ritualidad cotidiana. Estas personas también valoran y priorizan la colaboración mutua, el trabajo cooperativo y las enseñanzas de otros cuya experiencia es mayor. Lo más importante: el aprendizaje se concibe como actuación, se aprende 'haciendo' . Otro aspecto relevante es el espacio de autonomía permitido a los niños pequeños para que decidan la solución de algún problema, que es mucho mayor que en nuestra cultura; los adultos les dan el tiempo necesario, de acuerdo a cada niño o niña y a cada acción; si los niños se dan cuenta de que se equivocaron, se les espera para que corrijan por sí solos, intenten nuevamente y se les ayuda cuando lo solicitan, siendo notorio para nosotros, observadores de otra cultura, la poca presencia de instrucciones de los adultos en esas situaciones. Esto es, las personas mapuche valoran el aprendizaje de distintos caminos para llegar a la solución de un problema y actúan en consecuencia, demostrando gran respeto por los intereses de sus menores y por el propósito de sus acciones.

Un ejemplo en este sentido es lo relatado por un abuelo mapuche en el contexto de una conversación grupal, donde se analizaba lo que ellos consideran una gran diferencia entre la familia y la escuela: la falta de libertad en la escuela, por la exigencia que se hace a los niños para que hagan las cosas según determinadas instrucciones. Para relevar esta diferencia, el abuelo relató cómo dos de sus pequeñas nietas aprenden cuando la abuela cocina:

[las niñas] decían..., "yo voy a ir ayudar machacar ajo" y ponían el ajo con hoja y todo, o sea ... que no lo pelaron... [y la abuela] no le decía, "no así no”, sino que lo dejaba (...), yo creo que eso es importante, no lo hacen bien todavía, pero está[n] haciendo algo que ayuda pa' (sic) la comida" (Generación 1, hombre, familia de Hueichahue) ${ }^{3}$.

Al Taller de co-construcción de una dimensión intercultural para el currículo nacional, realizado en el marco de nuestra investigación en enero de 2013 en Afunalhue, asistieron más de 70 personas mapuche de La Araucanía y de Los Ríos (aprox. un $70 \%$ de las personas mapuche que participan en el estudio), entre ellos Lonkos, Dirigentes Territoriales, Profesores y Educadores Tradicionales que habían integrado previamente las conversaciones individuales, familiares y los encuentros por comunidad y por región realizados en los dos primeros años del estudio.

Transcripción Grupo Conversación Nueva Imperial, Octubre 2012. 
Para que estas valoraciones y prioridades estén presentes en el aula, resulta fundamental que los educadores tradicionales y los docentes mapuche tengan la libertad y, más que eso, sean motivados a propiciar modos de relación que son habituales en su cultura, con materiales adecuados a tal propósito, y no 'capacitados' para, en este sentido, parecerse lo más posible a un profesor formado en la cultura dominante. Más aún cuando estos modos de relación propios de la cultura mapuche son absolutamente coincidentes con el discurso educativo nacional aceptado por todos: la escuela debe formar personas responsables, respetuosas de los otros, solidarias, autónomas y creativas.

Nuestros estudios previos en esta misma línea ${ }^{4}$ han constatado que las lógicas que guían el quehacer de las personas mapuche en el contexto familiar son muchas veces distintas $\mathrm{e}$, incluso, contradictorias con las que imperan en nuestra cultura escolar. Proporcionamos tres ejemplos para ilustrar esto. Existe una temporalidad distinta en las acciones de los adultos respecto de las acciones de los niños: los adultos mapuche esperan a sus niños, no los apuran, no acotan sus acciones o las terminan por ellos, cuestión totalmente opuesta a lo que, en general, ocurre en la dinámica habitual de las salas de clases. Otro aspecto relevante, que ya se indicó antes, es la mayor autonomía que los adultos mapuche permiten a sus niños pequeños, por lo que ellos aprenden a temprana edad a resolver situaciones por sí solos, creando sus propias estrategias; autonomía que hemos visto desdibujarse hasta prácticamente desaparecer en la salas de clases, donde se dan instrucciones específicas para toda actividad. La habitual colaboración entre los integrantes del grupo familiar y de la comunidad que caracteriza al pueblo mapuche, resulta muchas veces contradictoria con la priorización de la individualidad y de la competencia que observamos habitualmente en el aula escolar (Ibáñez, 2010a, 2010b, 2006; Díaz y Druker, 2007).

La pertinencia cultural y lo participativo, que son aspectos considerados prioritarios para el desarrollo humano (FAO-CONADI, 2011), debiesen considerar esa participación desde la perspectiva de los actores, desde sus propios modos de comprender el mundo, desde las lógicas propias que guían su convivencia y la convivencia con la sociedad mayor. En otras palabras, se debe asegurar la real pertinencia cultural de los programas y de su implementación, ya que uno de los desafíos que tiene el Chile actual es cambiar la manera de hacer las cosas en educación y desarrollo, para contribuir a destrabar el futuro (PNUD, 2009) en lo que concierne a la relación entre la sociedad mayor, el estado y los pueblos originarios.

Dado que, como concluye Stavenhagen (2006), en los programas de educación y desarrollo dirigidos a la población indígena las brechas de la implementación constituyen uno de los principales obstáculos para el logro de sus propósitos y objetivos, disminuir esas brechas requiere de cambios en los enfoques de las políticas públicas y en las lógicas presentes en su diseño, para que el punto de partida no sea "la existencia de personas con necesidades que deben ser asistidas, sino sujetos con derecho a demandar determinadas prestaciones y conductas" (Abramovich, 2006: 36). La incorporación del SLI, y con ello la inclusión creciente de profesores y educadores tradicionales mapuche a las escuelas que conformarán numerosas tríadas culturales-contextuales, podría ser el inicio de un camino posible de educación intercultural para todos y todas, terminando con la confusión que parece existir hasta ahora entre proyecto intercultural y proyecto para indígenas. Como plantean Ansión et al.: "nuevas formas de ciudadanía en una perspectiva intercultural suponen el surgimiento de nuevos tipos de líderes, ellos mismos interculturales y conscientes

Proyectos Fondecyt $N^{\circ} 100078,1020496$ y 1060230 y Proyectos Fonide $N^{\circ} 274$ y N 55. 
de la necesidad de articular formas de organización y comprensión de la realidad, que se originen en un debate fecundo entre modos diversos de acercarse al mundo y a los problemas de la vida" (2007: 61).

Nuestros resultados preliminares evidencian que el nodo crítico de la implementación de la EIB para las personas pertenecientes al pueblo mapuche no está en los contenidos abordados en la escuela, sino, principalmente, en los 'modos de hacer las cosas' propios de cada cultura, los que responden a diferentes marcos lógicos, a distintos sistemas de conocimiento. No obstante, como ninguna cultura es pura, habrá múltiples puntos de encuentro entre los modos de hacer las cosas en cada cultura, que son los que nuestro estudio pretende identificar, de manera tal que permitan, desde allí, que se puedan levantar propuestas cuya condición primera sea la pertinencia cultural, reconocida como tal por quienes pertenecen a la cultura distinta a la dominante.

Si la dupla pedagógica configura un espacio intercultural, esto es, en igualdad de condiciones en cuanto al estilo interaccional que se propicia para implementar el currículo en la sala de clases, y si en este espacio se consideran y valoran los aprendizajes que los niños y niñas mapuche traen desde sus hogares, especialmente en cuanto a sus modos de relación, a la temporalidad aprendida para dar respuestas verbales o de ejecución, y a poder decidir la solución o ejecución de una determinada actividad sin la exigencia de seguir la instrucción dada como único camino permitido, entonces, los puntos de encuentro pertinentes tanto al contexto particular de cada aula y comunidad como a los contenidos del nivel escolar del cual se trate, surgirán naturalmente. Con ello, surgirá la posibilidad de concretar las bases para una educación realmente intercultural, de diálogo entre culturas, mucho más coherente con el discurso educativo oficial, que pueda también impactar en la formación docente y, consecuentemente, en la educación de todos los niños y niñas que asisten al sistema escolar chileno.

\section{REFERENCIAS BIBLIOGRÁFICAS}

Abramovich, V. (2006). Una aproximación al enfoque de derechos en las estrategias y políticas de desarrollo. Revista de la CEPAL, (88), 35-50.

Acuña, M. E. (2012). Perfil de educadores tradicionales y profesores mentores en el marco de la implementación del Sector de Lengua Indígena. Santiago: UNICEF/MINEDUC.

Anaya, J. (2005). Los pueblos indígenas en el derecho internacional. Madrid: Trotta.

Ansión, J., Turbino, F., Alfaro, S., González, M. E., Mujica, L., Segato, R. y Villasante, M. (Eds.). (2007). Educar en ciudadanía intercultural. Lima: Fondo Editorial PUCP-UFRO.

. (2007). La interculturalidad y los desafíos de una nueva forma de ciudadanía. En J. Ansión, F. Tubino, S. Alfaro, M. E. González, L. Mujica, R. Segato y M. Villasante (Eds.), Educar en ciudadanía intercultural (pp. 37-62). Lima: Fondo Editorial PUCP-UFRO.

Carihuentro, S. (2007). Saberes mapuche que debiera incorporar la educación formal en contexto interétnico e intercultural según sabios mapuche. Tesis de Magíster en Educación con Mención en Currículum y Comunidad Educativa. Santiago: Universidad de Chile.

Carvajal, R. y Dresdner, D. (2012). Cultura mapuche en el currículo nacional. El pulso de la interculturalidad en Chile. Tercer Congreso Latinoamericano de Antropología. Recuperado el 15 de julio de 2013 desde www.facso.uchile.cl/antropologia/ala2012

Comisión Económica para América Latina y el Caribe (2012). Desigualdades territoriales y exclusión social del pueblo mapuche en Chile. Santiago: CEPAL. 
Estudios Pedagógicos XLI, N 1: 323-335, 2015

LA TRÍADA CULTURAL-CONTEXTUAL: UNA OPORTUNIDAD PARA ASEGURAR LA PERTINENCIA CULTURAL EN LA IMPLEMENTACIÓN DE LA EDUCACIÓN INTERCULTURAL

Díaz, T. y Druker, S. (2007). La democratización del espacio escolar: Una construcción en y para la diversidad. Estudios Pedagógicos, vol.33 (1), 63-77.

FAO-CONADI (2011). Informe FAO-CONADI-Programa Orígenes. Santiago: FAO-CONADI.

Fernández, F. (2003). Hacia la construcción de una educación pertinente: La Educación Intercultural Bilingüe en la primera región. Tesis de Licenciatura en Antropología. Santiago: Universidad Academia de Humanismo Cristiano.

García, M. E. (2008). Desafíos de la interculturalidad. Educación, desarrollo e identidades indígenas en el Perú. Lima: Instituto de Estudios Peruanos.

Gobierno de Chile (2011). Informe sobre el papel de las lenguas indígenas en la promoción y protección de los derechos e identidad de los pueblos originarios en Chile. Recuperado el 23 de mayo de 2012 desde http://www.ohchr.org/Documents/Issues/IPeoples/EMRIP/StudyLanguages/Chile.pdf (2008). Reconocer: Pacto social por la multiculturalidad. Santiago: MIDEPLAN.

Hevia, R. (2005). Culturas originarias: Integración y desarrollo de nuestra diversidad. En B. Negrón y M. Nett (Eds.), Diversidad cultural. El valor de la diferencia (pp. 99-112). Santiago: LOM.

Ibáñez, N., Díaz, T., Druker, S. y Rodríguez, M. S. (2012). La comprensión de la diversidad en interculturalidad y educación. Convergencia. Revista de Ciencias Sociales, vol.19 (59), 215-240.

Ibáñez, N. (2010a). El contexto interaccional y la diversidad en la escuela. Estudios Pedagógicos, vol.36 (1), 275-286.

(2010b). La atención pedagógica a la diversidad. Estudio en aulas de escuelas rurales de comunidades mapuche del sur de Chile. Educación Superior y Sociedad, vol.15 (2), 83-110.

., Druker, S. y Rodríguez, M. S. (2009). Saber pedagógico y práctica docente en escuelas rurales de comunidades mapuche de la Región de la Araucanía. Estudio comparativo con escuelas de la Región Metropolitana. Informe Final Proyecto FONIDE N55. Santiago: UMCE.

(2006). La comprensión de lo diverso como condición de la calidad educativa. Investigaciones en Educación, vol.6 (2), 73-86.

Leyton, M., Mancilla, P., Navarrete, V. y Painean, P. (2005). Noción de Educación Intercultural Bilingüe en experiencias educativas de dos escuelas ubicadas en comunidades mapuche de la IX Región. Tesis de Licenciatura en Educación. Temuco: Universidad Católica de Temuco.

Lobos, J. y Águila, M. (2004). La educación como construcción social y la Educación Intercultural Bilingüe. Revisión crítica de una propuesta enfocada en los casos de Trapa-Trapa y Puerto Choque. Tesis de Licenciatura en Antropología. Valdivia: Universidad Austral de Chile.

Miller, A. (2012). La falta de desarrollo debido a la carencia de igualdad: La ineficacia del Programa de Educación Intercultural Bilingüe como factor de continuación de la dominación del Estado de Chile contra el Pueblo Mapuche. Independent Study Project (ISP) Collection. Paper 1342. Recuperado el 22 de julio de 2013 desde http://digitalcollections.sit.edu/isp_collection/1342

MINEDUC y UNICEF (2012). Educación para preservar nuestra diversidad cultural. Desafíos de implementación del Sector de Lengua Indígena en Chile. Santiago: UNICEF-MINEDUC.

MINEDUC (2012). Resultados SIMCE 2011. Recuperado el 10 de julio de 2013 desde www. simce.cl/index.php?id=421

(2011). Estudio sobre la implementación del Programa Intercultural Bilingüe PEIBOrígenes. Santiago: MINEDUC.

(2010). Resultados SIMCE 2009. Recuperado el 4 de julio de 2010 desde www.mineduc.cl (2009). Decreto 280 del 22 de septiembre de 2009. Santiago: MINEDUC.

(2000). Desafíos y fundamentos del Programa de Educación Intercultural Bilingüe.

Santiago: MINEDUC.

Ministerio de Desarrollo Social (2013). CENSO 2012. Santiago: MIDEPLAN. (2012). Resultados Encuesta CASEN 2011. Santiago: MIDEPLAN.

Ministerio de Planificación/Corporación Nacional de Desarrollo Indígena (2010). Informe Final Programa de Desarrollo Indígena MIDEPLAN-BID-Orígenes Fase II. Santiago: MIDEPLANCONADI. 
Montecinos, C. (2004). Analizando la política de Educación Intercultural Bilingüe en Chile desde la educación multicultural y reconstructivista. Cuadernos Interculturales, vol.2 (3), 25-32.

Naciones Unidas (2013). Informe de recomendaciones a Chile. Comité para la eliminación de la discriminación racial. Recuperado el 12 de octubre de 2013 desde http://www.politicaspublicas. net/panel/inf-dh/ddhh-chile/1669-cerd-chile-2013.html

(2009). Informe Naciones Unidas. Examen CERD Chile. Recuperado el 23 de septiembre de 2013 desde http://tbinternet.ohchr.org/_layouts/treatybodyexternal/Download.aspx?symbolno=C ERD $\% 2 \mathrm{fC} \% 2 \mathrm{fCHL} \% 2 \mathrm{fCO} \% 2 \mathrm{f} 19-21 \&$ Lang=en

Organizaciones Territoriales Mapuche (2006). Propuestas de Organizaciones Territoriales Mapuche al Estado de Chile. Recuperado el 23 de mayo de 2012 desde http://www.azkintuwe.org/ propuesta_mapuche2007.pdf

Programa de las Naciones Unidas para el Desarrollo (2009). Informe de Desarrollo Humano en Chile 2009. Santiago: PNUD.

y Gobierno de Chile (2008). Proyecto Apoyo al Desarrollo de la Política Indígena en Chile 2008-2009. Santiago: PNUD-Gobierno de Chile.

Prada, F. (2003). Conocimientos locales y diversificación curricular. Boletín Informativo PROEIB Andes, (61). Recuperado el 4 de enero de 2009 desde http://www.proeibandes.org/investigacion/ conocimientos_locales_y_diversificacion_curricular.pdf

Quintrileo, C., Yañez, C. y Valenzuela, C. (2013). Una aproximación crítica a la propuesta en consulta del Programa de Educación Intercultural Bilingüe (PEIB) en Chile. LOGOS. Revista de Lingüística, Filosofía y Literatura, vol.23 (1), 45-61.

Riedeman, A. (2008). La Educación Intercultural Bilingüe en Chile: ¿Ampliación de oportunidades para alumnos indígenas? INDIANA, (25), 169-193.

Rother, T. (2005). Conflicto intercultural y educación en Chile: Desafíos y problemas de la Educación Intercultural Bilingüe (EIB) para el Pueblo Mapuche. Revista Austral de Ciencias Sociales, (9), 71-84.

Schmelkes, S. (2006). La interculturalidad en la educación básica. Revista PRELAC, (3), 120-127.

Serrano, C. y Rojas, C. (2003). El desarrollo desde la perspectiva del pueblo mapuche. Serie de Estudios Socio/Económicos CIEPLAN, (19), 1-55.

Stavenhagen, R. (2006). Intervención oral del Sr. Rodolfo Stavenhagen, Relator Especial sobre la situación de los derechos humanos y las libertades fundamentales de los indígenas. Foro Permanente para las Cuestiones Indígenas. Nueva York, Estados Unidos. Recuperado el 22 de mayo de 2015 desde http://www.unhchr.ch/huricane/huricane.nsf/view01/9D82A182BE24A265C125717 8004373C6?opendocument

Sur Profesionales Consultores (2010). Evaluación Intermedia Programa Orígenes. Informe Final. Santiago: SPC.

Zúñiga, M. y Ansión, J. (1997). Interculturalidad y educación en el Perú. Lima: Foro Educativo. 
